\title{
Synthesis of Hard Magnetic Nd-Fe-B Powders by a Thermochemical Process
}

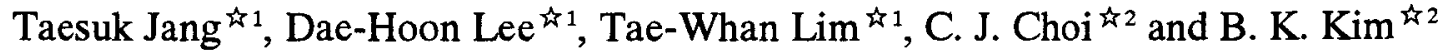 \\ 41 Division of Materials and Chemical Engineering, Sunmoon University, Asan, Choongnam 336-708, Korea \\ ${ }^{2}$ Nanopowder Materials Group, Korea Institute of Machinery \& Materials, Changwon, Kyungnam 640-010, Korea
}

Received August 6, 2003

\begin{abstract}
SYNOPSIS
Fabrication of Nd-Fe-B magnetic powders by R-D process using spray-dried precursors was tried. Due to stable formation of $\alpha-\mathrm{Fe}$ as a primary phase as same as that in ingots, the hard magnetic $\mathrm{Nd}_{2} \mathrm{Fe}_{14} \mathrm{~B}$ phase was not formed in the alloy powder with the composition of stoichiometric $\mathrm{Nd}_{2} \mathrm{Fe}_{14} \mathrm{~B}$ unless excessive amount of $\mathrm{Nd}$ precursor or $\mathrm{Ca}$ was added in the process. However, this excessive addition, especially for $\mathrm{Ca}$, led to abnormal grain growth of $\mathrm{Nd}_{2} \mathrm{Fe}_{14} \mathrm{~B}$. On the contrary, $\mathrm{Nd}_{2} \mathrm{Fe}_{14} \mathrm{~B}$ was successfully obtained as a major phase from the alloy powder with the composition of $\mathrm{Nd}_{15} \mathrm{Fe}_{77} \mathrm{~B}_{8}$ without such excessive addition. The size of spherical shape $\mathrm{Nd}_{2} \mathrm{Fe}_{14} \mathrm{~B}$ particles mostly consisted of one or more subgrains was less than $1 \mu \mathrm{m}$. The coercivity measured from this powder was relatively low $(\sim 3 \mathrm{kOe})$ mostly due to residual $\mathrm{CaO}$ and soft magnetic phases.

KEYWORDS
\end{abstract}

Nd-Fe-B, R-D process, Spray drying, Magnetic powder

\section{Introduction}

$\mathrm{Nd}-\mathrm{Fe}-\mathrm{B}$ magnetic powders for making sintered or bonded $\mathrm{Nd}-\mathrm{Fe}-\mathrm{B}$ magnets are commonly prepared by crushing Nd-Fe-B ingots or melt-spun flakes, which need additional energy and increase the production cost because of using high-purity metals as starting materials. One inexpensive alternative way is to prepare the $\mathrm{Nd}-\mathrm{Fe}-\mathrm{B}$ powders by reduction-diffusion (R-D) process $^{1-3}$ that was originally applied for the preparation of $\mathrm{SmCo}_{5}$ alloys. Typically, in this process, neodymium oxides are reduced by calcium in the presence of iron or iron oxide and the $\mathrm{Nd}_{2} \mathrm{Fe}_{14} \mathrm{~B}$ phase is formed simultaneously by solid state diffusion. The reacted alloy powder is then washed with water or dilute acid to remove calcium oxide and dried. Currently, this method is applied to prepare magnetic powders only for making sintered Nd-Fe-B magnets.

Meanwhile, spray drying has been widely use for preparing granulated powders of ferrites, carbides, nitrides, titanates, and other electrical ceramics. Not only it provides uniformly dispersed components, allowing exact composition control of a desired compound, but also it is possible to obtain fine particles of the final product. It has been shown that the size of final Nd-Fe-B product of R-D process depends on the size of starting iron powder ${ }^{4,5}$. Furthermore, when superfine precursors were employed in
R-D process, the reaction temperature and the reaction time were significantly reduced, resulting in small particulate powders ( $\sim 6 \mu \mathrm{m}$ in diameter) of Nd-Fe-B alloys ${ }^{5}$. It implies that uniformly distributed ultrafine Nd-Fe-B powders could be obtained if the spray-dried precursors are used as starting materials for R-D process.

Therefore, using spray-dried precursors, we attempted to fabricate Nd-Fe-B magnetic powders with the target composition of stoichiometric $\mathrm{Nd}_{2} \mathrm{Fe}_{14} \mathrm{~B}$ and $\mathrm{Nd}_{15} \mathrm{Fe}_{77} \mathrm{~B}_{8}$, a typical composition of a commercial sintered magnet, by the R-D process in this paper, and the phase evolution in each process step and the magnetic properties of the final products were investigated.

\section{Experimental}

The raw materials used were $\mathrm{Nd}\left(\mathrm{NO}_{3}\right) 6 \mathrm{H}_{2} \mathrm{O}, \mathrm{FeCl}_{3} 6 \mathrm{H}_{2} \mathrm{O}$, and $\mathrm{H}_{3} \mathrm{BO}_{3}$. They were weighted and dissolved into deionized water to make the solutions for spray drying, with the target composition of $\mathrm{Nd}_{12} \mathrm{Fe}_{82} \mathrm{~B}_{6}$ (stoichiometric $\mathrm{Nd}_{2} \mathrm{Fe}_{14} \mathrm{~B}$ ) and $\mathrm{Nd}_{15} \mathrm{Fe}_{77} \mathrm{~B}_{8} .10 \%$ excess neodymium hydrate was weighted in to compensate neodymium loss during the reactions. Spray drying was performed at $250^{\circ} \mathrm{C}$ with nozzle rotation velocity of $11,000 \mathrm{rpm}$ and feed rate of aqueous solution of $20 \mathrm{ml} / \mathrm{min}$. so that $\mathrm{Nd}, \mathrm{Fe}$, and $\mathrm{B}$ components could be uniformly dispersed in the spray-dried 
precursors. These precursors were debound at $900^{\circ} \mathrm{C}$ for 2 hours in air to remove all of the volatile components and to form oxides. To obtain finer final products ${ }^{9}$, the debound oxide powders were milled for 20 hours under a vacuum in a sealed steel vial with steel balls $6.3 \mathrm{~mm}$ in diameter. The milled oxides were then hydrogenated at $800^{\circ} \mathrm{C}$ for 2 hours to reduce iron oxide to $\alpha-\mathrm{Fe}$. The hydrogen-reduced powders were mixed with granular calcium, with the mixing ratio of $\mathrm{Ca}$ to powder of $2: 1$, and compressed into compacts. The reduction-diffusion of the compacts was carried out at $1,000^{\circ} \mathrm{C}$ for 3 hours under a flowing $\mathrm{Ar}$ atmosphere. The reacted compacts were stirred in deionized water into a slurry state. The slurry was washed repeatedly using dilute acetic acid and water. Eventually, the $\mathrm{Nd}-\mathrm{Fe}-\mathrm{B}$ alloy powders were recovered and dried in a vacuum.

Phase identification of the powders was performed by $\mathrm{Cu} K_{\alpha} \mathrm{X}$-ray diffraction. Morphologies and microstructures of the powders were examined with a SEM and a TEM. The magnetic properties of the final powders were measured with a VSM with a maximum applied field of $20 \mathrm{kOe}$.

\section{Results and Discussion}

Fig. 1 shows X-ray diffraction patterns of the powders

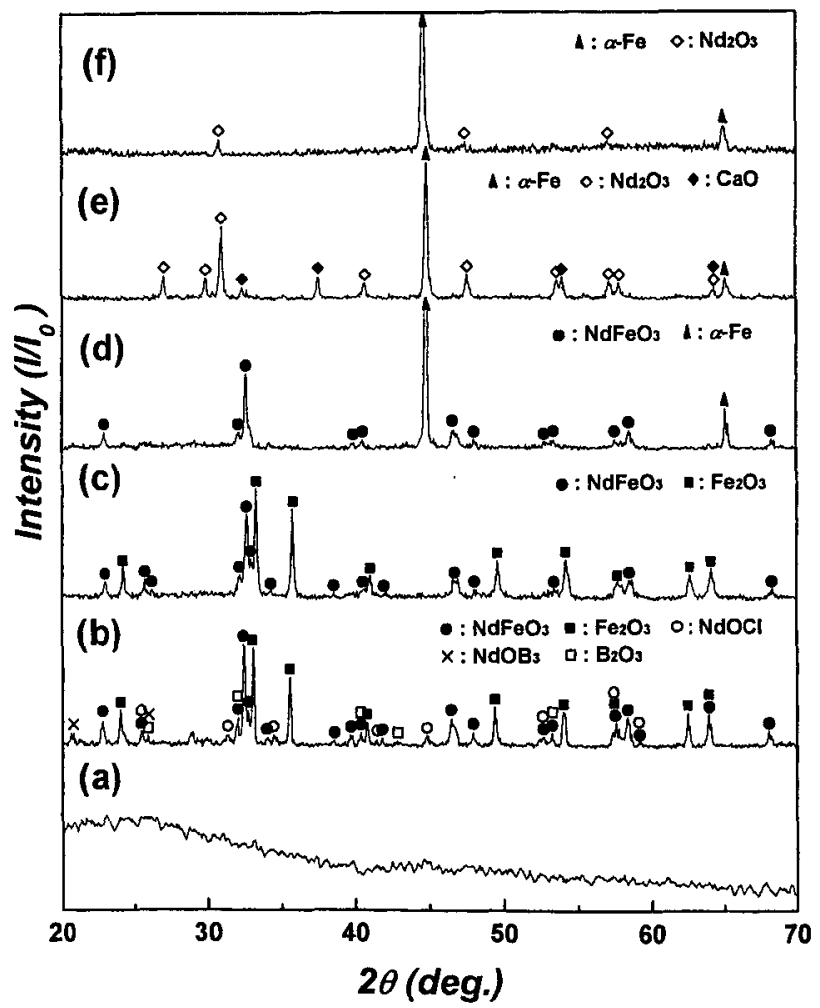

Fig.1 X-ray (Cu Ko) diffraction patterns of $\mathrm{Nd}_{2} \mathrm{Fe}_{14} \mathrm{~B}$ powders after (a) spray-dried, (b) debound at $900^{\circ} \mathrm{C}$ for $2 \mathrm{hrs}$., (c) ball milled for $20 \mathrm{hrs}$, (d) $\mathrm{H}_{2}$ reduced at $800^{\circ} \mathrm{C}$ for $2 \mathrm{hrs}$., (e) Ca reduced at $1000^{\circ} \mathrm{C}$ for $3 \mathrm{hrs}$. with $\mathrm{Ca}$ : powder $=2: 1$, and (f) washed and dried. obtained from the first step (i.e., spray drying) to the final one (i.e., washing and drying) of $R-D$ process for $\mathrm{Nd}_{12} \mathrm{Fe}_{82} \mathrm{~B}_{6}$ (stoichiometric $\mathrm{Nd}_{2} \mathrm{Fe}_{14} \mathrm{~B}$ ). As shown in Fig. 1(a), the spraydried precursor was amorphous whose morphologies were spherical shells $5 \sim 40 \mu \mathrm{m}$ in diameter. After debinding, as shown in Fig. 1(b), $\mathrm{NdFeO}_{3}$ and $\mathrm{Fe}_{2} \mathrm{O}_{3}$ (Hematite) were mainly formed with small $\mathrm{NdOCl}, \mathrm{B}_{2} \mathrm{O}_{3}$, and $\mathrm{NdBO}_{3}$. In fact, the debound product was mostly well-dispersed oxides of $\mathrm{Nd}, \mathrm{Fe}$, and B with finer particle size of $<2 \mu \mathrm{m}$ \%. This chemical mixture of oxides is one of the advantages of the present fabrication method because the chemically mixed one is more active for subsequent treatment than the mixture of coarser and/or mechanically mixed powders of oxides used as starting materials in previous work ${ }^{\eta}$. As can be seen in Fig. 1 (c), the minor phases such as $\mathrm{NdOCl}, \mathrm{B}_{2} \mathrm{O}_{3}$, and $\mathrm{NdBO}_{3}$ were not detected after milling. They seemed to be decomposed due to the mechanical stress generated during long-time milling. It has been shown that the milling before or after $\mathrm{H}_{2}$ reduction is a necessary step to obtain well-dispersed $\mathrm{Nd}_{2} \mathrm{Fe}_{14} \mathrm{~B}$ particles as final products ${ }^{\circ}$. After $\mathrm{H}_{2}$ reduction (Fig. 2(d)), $\mathrm{FeNdO}_{3}$ was still maintained, but $\alpha$-Fe was completely separated out from aggregated $\mathrm{Fe}_{2} \mathrm{O}_{3}$ (Hematite).

In $\mathrm{R}-\mathrm{D}$ process, $\mathrm{Nd}$-oxides are reduced by $\mathrm{Ca}$ in the presence of iron or iron oxide and $\mathrm{Nd}_{2} \mathrm{Fe}_{14} \mathrm{~B}$ phase is formed simultaneously by solid state diffusion ${ }^{2}$. Therefore, $\mathrm{Nd}_{2} \mathrm{Fe}_{14} \mathrm{~B}$ and $\mathrm{CaO}$ should be only remained after $\mathrm{Ca}$ reduction. However, as shown in Fig. 1(e), $\alpha$-Fe was still

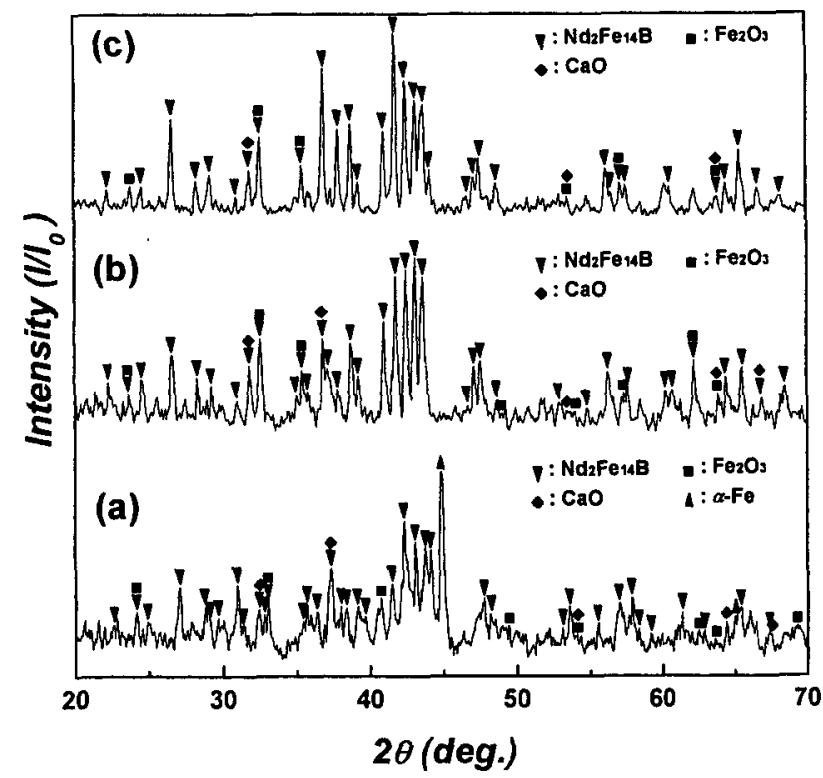

Fig.2 X-ray $(\mathrm{Cu} \mathrm{K} \alpha)$ diffraction patterns of $\mathrm{Nd}_{2} \mathrm{Fe}_{14} \mathrm{~B}$ powders after $\mathrm{Ca}$ reduced at $1000^{\circ} \mathrm{C}$ for $3 \mathrm{hrs}$. The mixing raito of $\mathrm{Ca}$ to powder of (a), (b), and (c) are $3: 1,5: 1$, and $7: 1$, respectively, with the addition of $25 \%$ excess $\mathrm{Nd}$. 
sustained as a major phase with $\mathrm{CaO}$ after $\mathrm{Ca}$ reduction, and other oxides such as $\mathrm{Nd}_{2} \mathrm{O}_{3}$ (A type, hexagonal) and soft magnetic $\mathrm{Fe}_{2} \mathrm{O}_{3}$ (Maghemite) were also formed, all due to insufficient reduction and diffusion. Consequently, the final powders obtained after washing and drying were mostly $\alpha$-Fe with small amount of $\mathrm{Nd}_{2} \mathrm{O}_{3}$. It was found that it is necessary to add more $\mathrm{Ca}$ and/or $\mathrm{Nd}$ in order to obtain $\mathrm{Nd}_{2} \mathrm{Fe}_{14} \mathrm{~B}$ phase from the stoichiometric $\mathrm{Nd}_{2} \mathrm{Fe}_{14} \mathrm{~B}$ composition.

In fact, when $25 \%$ excess $\mathrm{Nd}$-hydrate was added to the starting materials and the mixing ratio of $\mathrm{Ca}$ to powder increased as $3: 1,5: 1$, and $7: 1$, the $\mathrm{Nd}_{2} \mathrm{Fe}_{14} \mathrm{~B}$ phase was successfully formed as a major phase as shown in Fig. 2 . However, with the mixing ratio of $\mathrm{Ca}$ to powder of $3: 1$, $\alpha$-Fe still coexisted with $\mathrm{Nd}_{2} \mathrm{Fe}_{14} \mathrm{~B}$ (Fig. 2(a)), even when excessive amount of $\mathrm{Nd}$ was $30 \%$. And $\alpha$-Fe disappeared

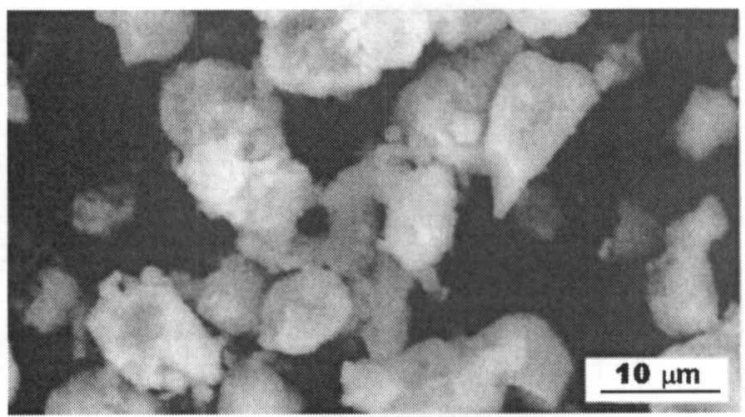

(a)

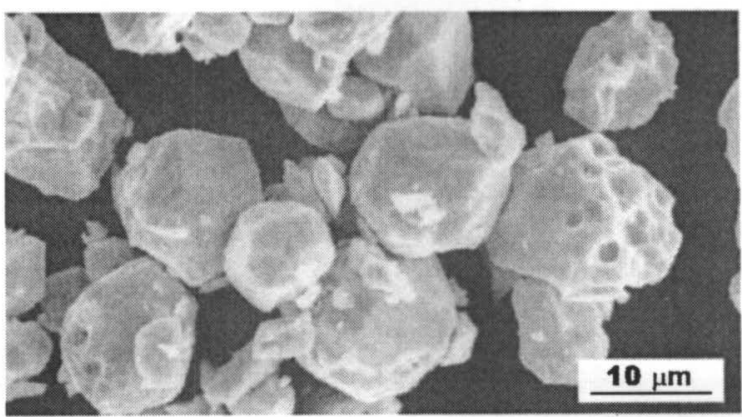

(b)

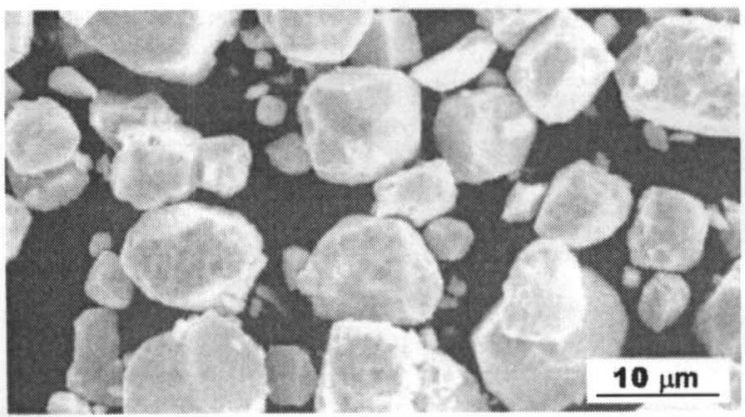

(c)

Fig.3 SEM images of $\mathrm{Nd}_{2} \mathrm{Fe}_{14} \mathrm{~B}$ powders after $\mathrm{Ca}$ reduced at $1000^{\circ} \mathrm{C}$ for $3 \mathrm{hrs}$. Ca: powder=(a) $3: 1$, (b) $5: 1$, and (c) $7: 1$, with the addition of $25 \%$ excess $\mathrm{Nd}$. completely only with the mixing ratio of more than $5: 1$. Unfortunately, as shown in Fig. 3, particles in the final products were grown abnormally with the increase of calcium dose, resulting in polyhedral particles with the size of $\leq 10 \mu \mathrm{m}$. It shows that excessive dose of $\mathrm{Ca}$ enhances the formation of $\mathrm{Nd}_{2} \mathrm{Fe}_{14} \mathrm{~B}$, but is harmful to obtain fine particles. Eventually, it deteriorates the magnetic properties of Nd-Fe-B powders (See Fig. 5(b)).

Above results suggest that it will not be easy to obtain the $\mathrm{Nd}-\mathrm{Fe}-\mathrm{B}$ powder consisted of $\mathrm{Nd}_{2} \mathrm{Fe}_{14} \mathrm{~B}$ single phase,

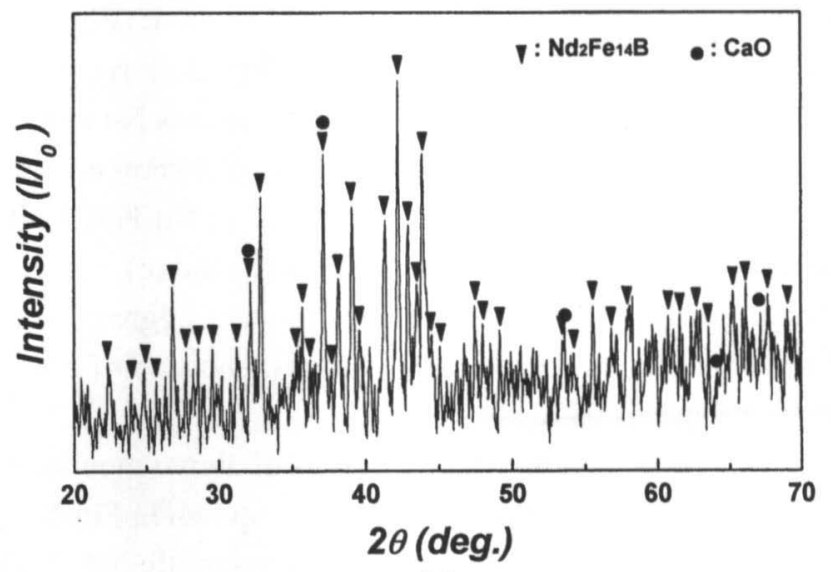

(a)

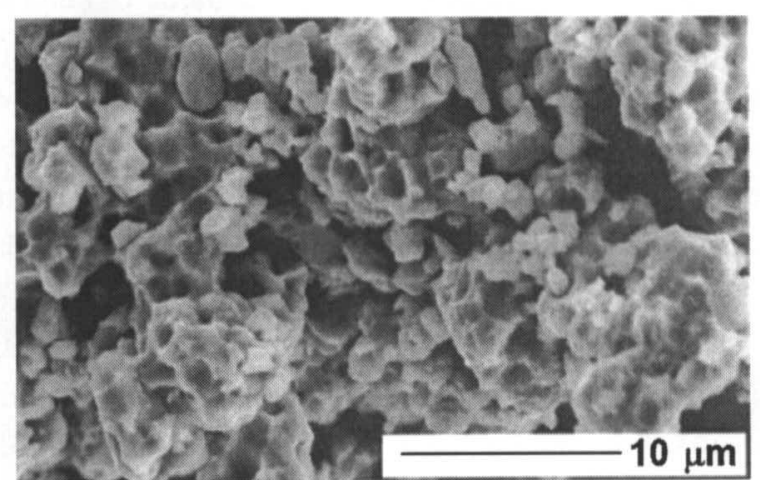

(b)

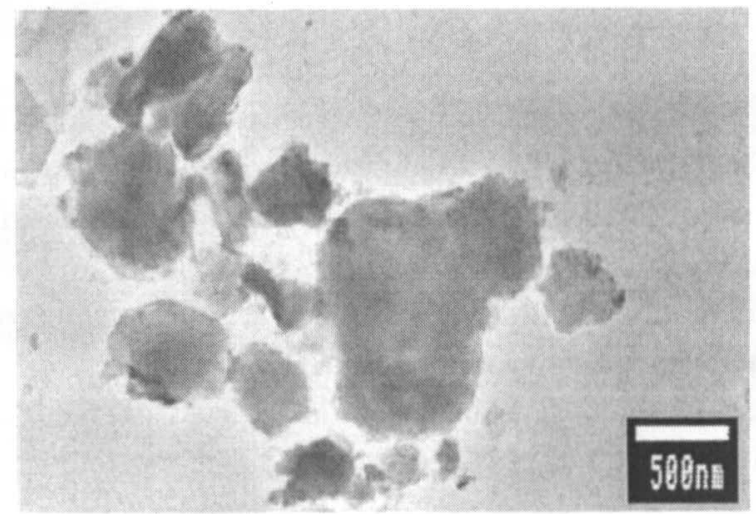

(c)

Fig.4 (a) X-ray $\left(\mathrm{Cu} \mathrm{K}_{\alpha}\right)$ diffraction pattern, (b) SEM image, and (c) TEM image of $\mathrm{Nd}_{15} \mathrm{Fe}_{77} \mathrm{~B}_{8}$ powder. 
whose composition is stoichiometric $\mathrm{Nd}_{2} \mathrm{Fe}_{14} \mathrm{~B}$, because $\alpha$-Fe is crystallized as a stable primary phase in the alloy powder as same as that in the ingot of the stoichiometric composition $^{8)}$. As demonstrated below, therefore, to fabricate the Nd-Fe-B powders mainly consisted of $\mathrm{Nd}_{2} \mathrm{Fe}_{14} \mathrm{~B}$ and exhibit reasonably high magnetic properties by the thermochemical process, it is desirable to choose a composition in which $\mathrm{Nd}$ is richer than that in the stoichiometric one.

When the target composition was $\mathrm{Nd}_{15} \mathrm{Fe}_{77} \mathrm{~B}_{8}$, in fact, the hard magnetic $\mathrm{Nd}_{2} \mathrm{Fe}_{14} \mathrm{~B}$ was formed as a major phase without the aid of too much excess Nd or Ca. Fig. 4(a) shows $x$-ray diffraction pattern obtained from the $\mathrm{Nd}_{15} \mathrm{Fe}_{77} \mathrm{~B}_{8}$ powder fabricated with $10 \%$ excess $\mathrm{Nd}$ and the mixing ratio of $\mathrm{Ca}$ to powder of $2: 1$. As shown in the figure, the powder was mostly composed of $\mathrm{Nd}_{2} \mathrm{Fe}_{14} \mathrm{~B}$ with some residual $\mathrm{CaO}$. As shown in Fig. 4 (b) and (c), particles of $\mathrm{Nd}_{2} \mathrm{Fe}_{14} \mathrm{~B}$ with the size of $<1 \mu \mathrm{m}$ were aggregated to form clusters. And each particle was composed of one or more subgrains of $\mathrm{Nd}_{2} \mathrm{Fe}_{14} \mathrm{~B}$.

Fig. 5 shows magnetization curves of above mentioned $\mathrm{Nd}_{2} \mathrm{Fe}_{14} \mathrm{~B}$ and $\mathrm{Nd}_{15} \mathrm{Fe}_{77} \mathrm{~B}_{8}$ powders. As shown in Fig. 5(a), $\mathrm{Nd}-\mathrm{Fe}-\mathrm{B}$ powders in which the hard magnetic $\mathrm{Nd}_{2} \mathrm{Fe}_{14} \mathrm{~B}$ phase were coexisted with the soft magnetic $\alpha$-Fe yielded very low coercivity and remanence (See Fig. 2 (a)). Unfortunately, increase of the mixing ratio of $\mathrm{Ca}$ to powder more than $5: 1$ to obtain fully developed $\mathrm{Nd}_{2} \mathrm{Fe}_{14} \mathrm{~B}$ phase in the stoichiometric composition deteriorated the magnetic properties further, as shown in Fig. 5(b), even though the major phase in the powder was $\mathrm{Nd}_{2} \mathrm{Fe}_{14} \mathrm{~B}$ (See Fig. 2(b)). On the other hand, as shown in Fig. 5 (c), the coercivity of $\sim 3.0 \mathrm{kOe}$ was obtained from $\mathrm{Nd}_{15} \mathrm{Fe}_{77} \mathrm{~B}_{8}$ powders without the aid of too much excess $\mathrm{Nd}$ or $\mathrm{Ca}$. Constriction of the loop in Fig. 5(c) at low applied field was mainly due to the residual soft magnetic phases.

\section{Conclusions}

Nd-Fe-B magnetic powders were fabricated by R-D process using spray-dried precursors. Unless excessive amount of $\mathrm{Nd}$ precursor or $\mathrm{Ca}$ was added, the hard magnetic $\mathrm{Nd}_{2} \mathrm{Fe}_{14} \mathrm{~B}$ phase was not formed in the alloy powder of stoichiometric $\mathrm{Nd}_{2} \mathrm{Fe}_{14} \mathrm{~B}$ because the soft magnetic $\alpha-\mathrm{Fe}$ was formed as a primary phase. However, the $\mathrm{Nd}_{2} \mathrm{Fe}_{14} \mathrm{~B}$ phase was fully developed in the alloy powder of $\mathrm{Nd}_{15} \mathrm{Fe}_{77} \mathrm{~B}_{8}$ without such excessive addition. The particle size of $\mathrm{Nd}_{2} \mathrm{Fe}_{14} \mathrm{~B}$ in $\mathrm{Nd}_{15} \mathrm{Fe}_{77} \mathrm{~B}_{8}$ powder was less than $1 \mu \mathrm{m}$. Magnetic properties of this powder was relatively poor, resulting in the coercivity of $\sim 3 \mathrm{kOe}$, mainly due to residual $\mathrm{CaO}$ and soft magnetic phases.
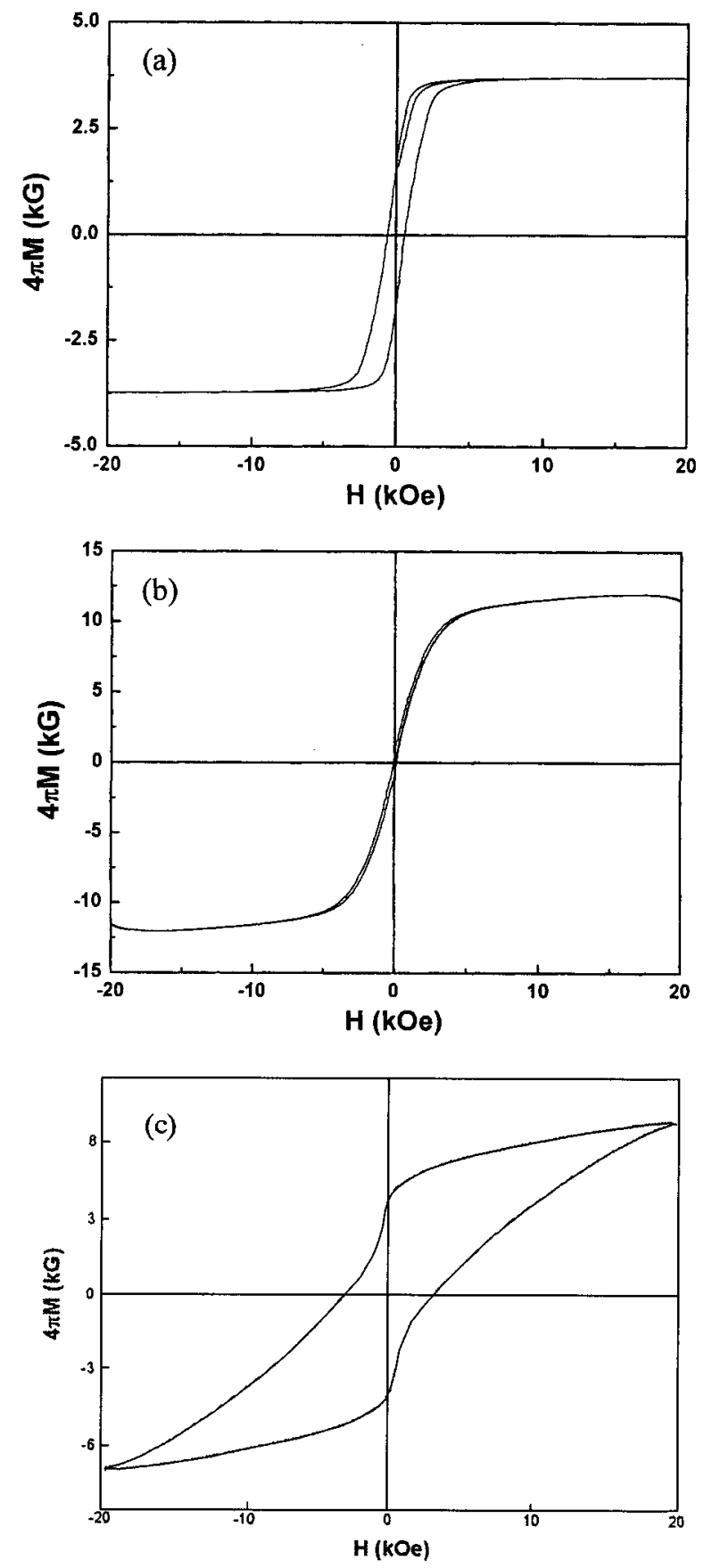

Fig.5 Hysteresis loops of $\mathrm{Nd}-\mathrm{Fe}-\mathrm{B}$ powders $\mathrm{Ca}$ reduced at $1000^{\circ} \mathrm{C}$ for $3 \mathrm{hrs}$. The mixing ratio of $\mathrm{Ca}$ to powder is (a) 3:1 and (b) $5: 1$, with the addition of $25 \%$ excess $\mathrm{Nd}$ to $\mathrm{Nd}_{2} \mathrm{Fe}_{14} \mathrm{~B}$ compostion. (c) The mixing ratio of $\mathrm{Ca}$ to powder is $2: 1$ with the composition of $\mathrm{Nd}_{15} \mathrm{Fe}_{77} \mathrm{~B}_{8}$.

\section{Acknowledgements}

This work is supported by dual use technology program (Grant No. 01-IT-MP-07) of Ministry of Commerce, Industry, and Energy. 


\section{References}

1) R.E.Cech: J. Met., 26(1974)32.

2) C.S.Herget: Metal. Powder Rep., 42(1987)438.

3) S.X.Zhou and R.T.Shuai: Proc. $9^{\text {th }}$ Int. Workshop on Rare Earth Magnets and their Applications, 1987, Bad Soden, (FRG), 339.

4) R.K.Sidhu: J. Alloys Compds, 346(2002)250.

5) J.H.Lin, S.F.Liu, Q.M.Cheng, X.L.Qian, L.Q.Yang and
M.Z.Su: J. Alloys Compds, 249(1997)237.

6) X.L.Dong, B.K.Kim, C.J.Choi, K.S.Park and Z.D.Zhang: J. Mater. Res., 16(2001)1083.

7) Y.Okajima, T.Tsugita, T.Takechi and S.Okada: US Patent No. 4(1987)681,623.

8) G.Schneider, E.Th.Henig, G.Petzow and H.H.Stadelmaier: Z. Metallkd, 77(1986)7. 